\title{
EDITORIAL
}

\section{A silver lining ...}

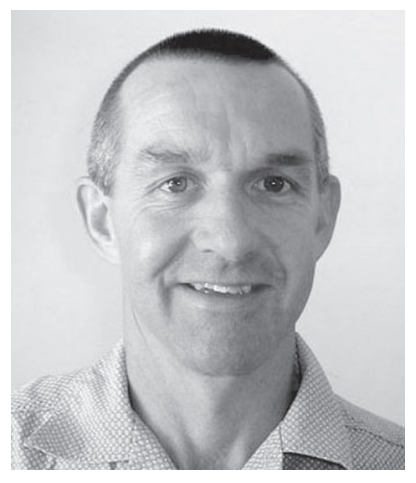

Who could have predicted at the start of 2009 that sex verification in sport would have received so much front page news all over the world? As with all matters complicated, following discussion and an exchange of views, there are always more questions than answers. In particular, when biological facts are made murky by cultural and sociological influences the number of unanswered questions increase exponentially. The risk for a polarisation of views is high. An attempt has been made to answer some of these questions in the review 'The science and management of sex verification in sport' by Tucker and Collins, published in this edition (p. 147). This review systematically provides some background and historical context to sex verification in sport and exposes some of the biological/ medical nuances. The IAAF consensus statement and the Canadian Academy of Sports Medicine recommendations on sex verification are presented. The different foci of these statements confirm the difficulty in reaching universal consensus. Clearly, there is a need to have specific guidelines for the South African context to provide a framework of reference for any similar cases in the future. Such guidelines will surely prevent a repeat of the debacle that occurred when Athletics South Africa (ASA) mismanaged the situation that transpired at the World Championships in Berlin in August 2009. In accordance, the Department of Sport has commissioned a document that will provide guidelines for managing sex verification in the South African context. The process of compiling the guidelines is being coordinated by $\mathrm{Dr}$ Ramagole and the final document will be published in this journal in 2010. Perhaps these guidelines will be the 'silver lining', resulting from the unfortunate series of events involving ASA, and will ensure that we avoid public scrutiny and subsequent humiliation of anyone with intersex characteristics in the future.

The term of the editorial board consisting of Professors Mars, Coopoo, Myburgh, Noakes, Rogers and Vaughan comes to an end with this edition of the journal. This editorial board has served for 11 years and their combined experience and wisdom has been a major factor in the growth of the journal. We thank them sincerely and trust that they will continue to support the journal in the capacity of either an author or a reviewer!

In 2010 there will be some exciting changes in the journal. The online version of the journal (www.sajsm.org.za) will be promoted locally and internationally. In 2009 we had visitors to the website from 45 countries - as the website is promoted more widely we expect this to increase substantially. Next year we will also have a section that will allow readers to earn CPD points by completing an online questionnaire on the contents of papers published in that issue. Also, the president of SASMA has negotiated a deal with the British Journal of Sports Medicine that will allow us to publish selected articles from that journal. He has organised prize money for the best paper published in the journal in 2010 - more details about this will follow early next year. In short, the journal has exciting times ahead! This will coincide with the world focus on South Africa before and during the FIFA World Cup - what an opportune time to show the country and the rest of the world how sports medicine has evolved to be inextricably linked to high-performance sport.

\section{Mike Lambert}

Editor-in-Chief 